\title{
A importância da enfermagem na orientação sobre o desmame precoce: uma revisão integrativa
}

The importance of nursing in providing guidance on early weaning: an integrative review

La importancia de la enfermería en la orientación sobre el destete temprano: una revisión integradora

Márcia Dias do Amor ${ }^{1}$, Shirley Nara Pontes da Silva ${ }^{1 *}$, Laize Nascimento Pereira ${ }^{1}$, Suelen Suzy Gomes Baptista², Graciana de Sousa Lopes¹.

\section{RESUMO}

Objetivo: Discutir por meio de uma revisão integrativa sobre os impactos do Desmame Precoce e a importância dos profissionais de enfermagem para o sucesso do aleitamento materno. Métodos: Trata-se de uma pesquisa do tipo revisão integ rativa da literatura, onde foram utilizados artigos cient íficos de 2011 a 2021, encontrados nas bases de dados SCIELO, LILACS, Acervo+ Index Base, Google Acadêmico e PubMed. Resultados: Selecionou-se 14 artigos dos quais emergiram 3 categorias: Os Impactos Gerados Pelo Desmame Precoce; Os Benefícios do Aleitamento Materno; A importância das Ações da Enfermagem para o sucesso do Aleitamento Materno Exclusivo. Essas categorias mostram que o desmame precoce pode ser influenciado por uma série de fatores como a of erta de outros tipos de alimentação antes que o bebê complete seis meses. Considerações finais: O leite materno é o melhor alimento para ser fornecido a criança desde o seu nascimento, até que esta complete os seis meses de vida, por ser completo e já está pronto, na temperatura ideal, tem baixo custo, devendo ser complementado com outros tipos de alimentos apenas a partir dos seis meses.

Palavras-chave: Mãe, Aleitamento materno, Desmame precoce, Benefícios e impactos.

\begin{abstract}
Objective: To discuss, through an integrative review, the impacts of Early Weaning and the importance of nursing professionals for the success of breastfeeding. Methods: This is an integrative literature review research, which used scientific articles from 2011 to 2021, found in the SCIELO, LILACS, Acervo+ Index Base, Academic Google and PubMed databases. Results: 14 articles were selected from which 3 categories emerged: The Impacts Generated by Early Weaning; The Benefits of Breastfeeding; The importance of Nursing Actions for the success of Exclusive Breastfeeding. These categories show that early weaning can be influenced by a number of factors, such as offering other types of food before the baby is six months old. Final considerations: Breast milk is the best food to be provided to children from birth, until they are six months old, as it is complete and ready, at the ideal temperature, it has a low cost, and should be supplemented with other types of food only after six months.
\end{abstract}

Key words: Mother, Breastfeeding, Early weaning, Benefits and impacts.

\footnotetext{
${ }^{1}$ Centro Universitário Faculdade Metropolitana de Manaus (CEUNI-FAMETRO), Manaus - AM.

*E-mail: shirley_narapontes@hotmail.com

2 Instituto Educacional Giga, Manaus - AM.
}

SUBMETIDO EM: 12/2021

ACEITO EM: 12/2021

PUBLICADO EM: 2/2022 


\begin{abstract}
RESUMEN
Objetivo: Discutir, a través de una revisión integradora, los impactos del Destete Temprano y la importancia de los profesionales de enfermería para el éxito de la lactancia materna. Métodos: Se trata de una investigación de revisión integradora de la literatura, que utilizó artículos científicos de 2011 a 2021, encontrados en las bases de datos SCIELO, LILACS, Acervo + Index Base, Academic Google y PubMed. Resultados: se seleccionaron 14 artículos de los cuales surgieron 3 categorías: los impactos generados por el destete temprano; Los beneficios de la lactancia materna; La importancia de las Acciones de Enfermería para el éxito de la Lactancia Materna Exclusiva. Estas categorías muestran que el destete temprano puede verse influenciado por una serie de factores, como ofrecer otros tipos de alimentos antes de que el bebé cumpla seis meses. Consideraciones finales: La leche materna es el mejor alimento para brindar a los niños desde el nacimiento, hasta los seis meses de edad, ya que está completa y lista, a la temperatura ideal, tiene un bajo costo y debe complementarse con otros tipos de comida solo después de seis meses.
\end{abstract}

Palabras clave: Madre, Lactancia materna, Destete precoz, Beneficios e impactos.

\title{
INTRODUÇÃO
}

O Ministério da Saúde (2015) aponta que a amamentação está avante ao suprimento nutricional para a criança, pois envolve o relacionamento proximal entre a mãe e o filho, além de ser a melhor estratégia de promoção de vínculo entre eles, o que acarreta em af eto e proteção para o bebê, e impacta diretamente no estado nutricional da criança.

Para que a criança se desenvolva de forma saudável a amamentação é fundamental, pois estima-se que o Aleitamento Materno (AM) impele cerca de 13\% da mortalidade, pelas causas nomeadas de evitáveis, de crianças com idade igual ou inferior a 5 anos. É fato comprovado que promover o AM na primeira hora de vida da criança traz como consequência a proteção contra agravos como as infecções respiratórias, alergias e diarreias, além de oportunizar benefícios como o melhor desenvolvimento cerebral, reduz custos monetários para o ceio familiar e Governo, e a redução de chances de desenvolver: obesidade, diabetes, altos níveis de colesterol e hipertensão arterial (BRASIL, 2018).

De acordo com Silva JN (2020), a interrupção do Aleitamento Materno Exclusivo (AME) antes que o bebê complete seis meses de vida é denominado Desmame Precoce (DP). Note-se que, em geral, as grávidas, bem como as lactantes conhecem a importância de amamentar, assim como o tempo necessário para esse ato, contudo não a executam eficazmente. $O$ autor também afirma que, a interrupção do Ame onera à criança algumas consequências e dentre as principais estão a incidência de hospitalização e quadros diarreicos que acarretam, consequentemente, no índice de mortalidade infantil; a formação incompleta do motor-oral; ocorrência de alergias alimentaras, etc. Assim, o DP causa mudanças negativas aos bebês.

Segundo Marques ES, et al. (2011), as expressões "leite fraco", "pouco leite" e de que "o leite secou" são alguns argumentos comuns entre as mães para que se introduzam outros alimentos de forma precoce na dieta do bebê e, em virtude do aspecto do leite, muitas dessas genitoras acreditam produzir insuficiente quantidade de leite para nutrir seus bebês.

O alimento considerado o mais completo e suficiente para a manutenção do crescimento e desenvolvimento salutar do bebê em seus seis primeiros meses de vida é o Leite Materno (LM), pois de acordo com Leão E, et al. (2015), é de fácil digestão, assim como é assimilado de forma completa pelo organismo infantil, além de possuir mecanismos e ingredientes que promovem à criança proteção contra inúmeras doenças por ser uma fonte natural de lactobacilos, bifidobactérias e oligossacarídeos. Assim, o leite humano também é o único nutrimento que of erta peculiaridades imunológicas.

Schneider A, et al. (2019) relatam que, esse alimento tem em si uma composição viva de 160 substâncias como proteínas, gorduras, células e carboidrato, a qual é ativamente protetora e imunomoduladora, que também contém células vivas e uma variedade imensa de fatores ativos biológicos e uma quantidade hormonal vasta como a tiroxina, os esteroides, as gonadotrofinas, a melatonina, a prolactina, a eritropoietina entre outros. 
Conforme Costa EC (2012) algumas dessas substâncias geram benefícios como a lactoferrina que incide na estimulação do crescimento de inúmeros tipos de células imunológicas, bem como na fabricação de anticorpos. A alta concentração de proteínas lácteas, singularmente a $\lg \mathrm{A}$ e a $\lg \mathrm{G}$ que promovem ao neonato uma imunidade passiva, onerando no amadurecimento dos tecidos epiteliais gastrointestinais, protegendo $o$ organismo do Recém-Nascido (RN) contra vírus mortais e bactérias.

As mães que praticam o DP alegam fazerem uso de antibióticos em virtude de patologias; assim como o tempo que passam fora em decorrência de trabalho; mamas feridas; a recusa do RN em fazer a pega da mama, principalmente quando a genitora of erta o leite via mamadeiras e depois of erecem o peit o, o que acaba registrando a recusa do bebê (ARAÚJO OD, et al., 2008; SILVA JN, 2020).

O Ministério da Saúde (2019), afirma que, a introdução de acessórios como a chupeta é um fator que leva ao DP e interfere no número de mamadas no decorrer do dia, o que torna seu uso não recomendado, uma vez que podem onerar em deformidades anatômicas como o desalinhamento dos dentes e imperfeições na fala, na respiração e na mastigação. Outra questão negativa gerada pelo uso de chupetas é a dificuldade de sucção no peito da mãe por confundi-los, uma vez que o bico desse aparato diverge do bico do seio da mãe.

Este estudo é relevante ao se perceber o quão é importante o acompanhamento realizado por profissionais da saúde no que cerne ao aleitamento materno, promovendo ações para que o DP seja evitado, como prestando auxílio às mães, sanando todas as dúvidas destas, orientando-as quanto a práticas de $A M$, além de dar acompanhamento ao binômio mãe-bebê, priorizando a saúde da criança, bem como imprimir o comprometimento de todos do ceio familiar, uma vez que os hábitos alimentares do bebê inicia em casa, mediante a observação das práticas alimentares de seus familiares (MINISTÉRIO DA SAÚDE, 2015).

O objetivo deste estudo foi discutir por meio de uma revisão integrativa sobre os impactos do Desmame Precoce e a importância dos profissionais de enfermagem para o sucesso do aleitamento materno.

\section{MÉTODOS}

Este estudo foi elaborado por meio de uma revisão integrativa de literatura que segundo Botelho LLR, et al. (2011), é uma busca realizada na literatura, de artigos científicos com fontes de conhecimento atual que responda uma questão problema, para por fim obter respostas que determine a veracidade de tal conhecimento.

As bases de dados que embasaram esta pesquisa foram as bibliotecas eletrônicas como Scientific Eletronic Library Online (SCIELO), Literatura Latino-Americana e do Caribe em Ciências da Saúde (LILACS), Acervo+ Index Base, Google Acadêmico e PubMed. Os descritores disponibilizados na fonte DECS utilizados para a busca e coleta de dados nas bibliotecas virtuais foram: Mãe AND Aleitamento Materno AND Desmame Precoce AND Causas e Consequências.

As ações destacadas para a composição textual deste foram: aleitamento materno, vantagens proporcionadas pela amamentação, propriedades do aleitamento materno, prevenção de doenças através do aleitamento materno, imunidade materna, nutrição infantil e as consequências geradas pelo desmame precoce. Como critério de elegibilidade utilizou-se o aproveitamento das obras publicadas em formato completo, nas línguas portuguesa e inglesa, no período de 2011 a 2021. O recorte temporal, se justifica devido ao tema e foi importante expandir a busca por um tempo maior.

\section{RESULTADOS E DISCUSSÃO}

À medida que os materiais foram selecionados, foi feito a leitura minuciosa, crítica e interpretativa, onde se analisou de forma objetiva as informações encontradas, o que constitui esta revisão. Os critérios de inelegibilidade utilizados na pesquisa incluíram materiais que não abordaram a temática em questão ou foram publicados em formato de resumo ou, Monografias, Dissertações de Mestrado e teses de Doutorado.

Durante a pesquisa encontrou-se 128 artigos que abordavam a temática aqui proposta. Foram excluídas 18 duplicatas encontradas, restando 110 artigos. Em seguida foi realizada a leitura parcial desses artigos, 
sendo 22 excluídos pelo formato (monografias, dissertação e etc.), totalizando 88 artigos. Por fim, foram excluídos 74 que não respondiam as questões de pesquisa. Apenas 14 artigos foram selecionados levandose em conta os critérios de elegibilidades propostos, sendo 4 da base de dados SCIELO, 1 da LILACS, 2 da Acervo+ Index Base, 6 do Google Acadêmico e 1 na base PubMed, no entanto, alguns artigos tiveram a indexação em mais de 1 base científica (Figura 1).

Figura 1 - Fluxograma dos critérios de inclusão e exclusão da pesquisa.

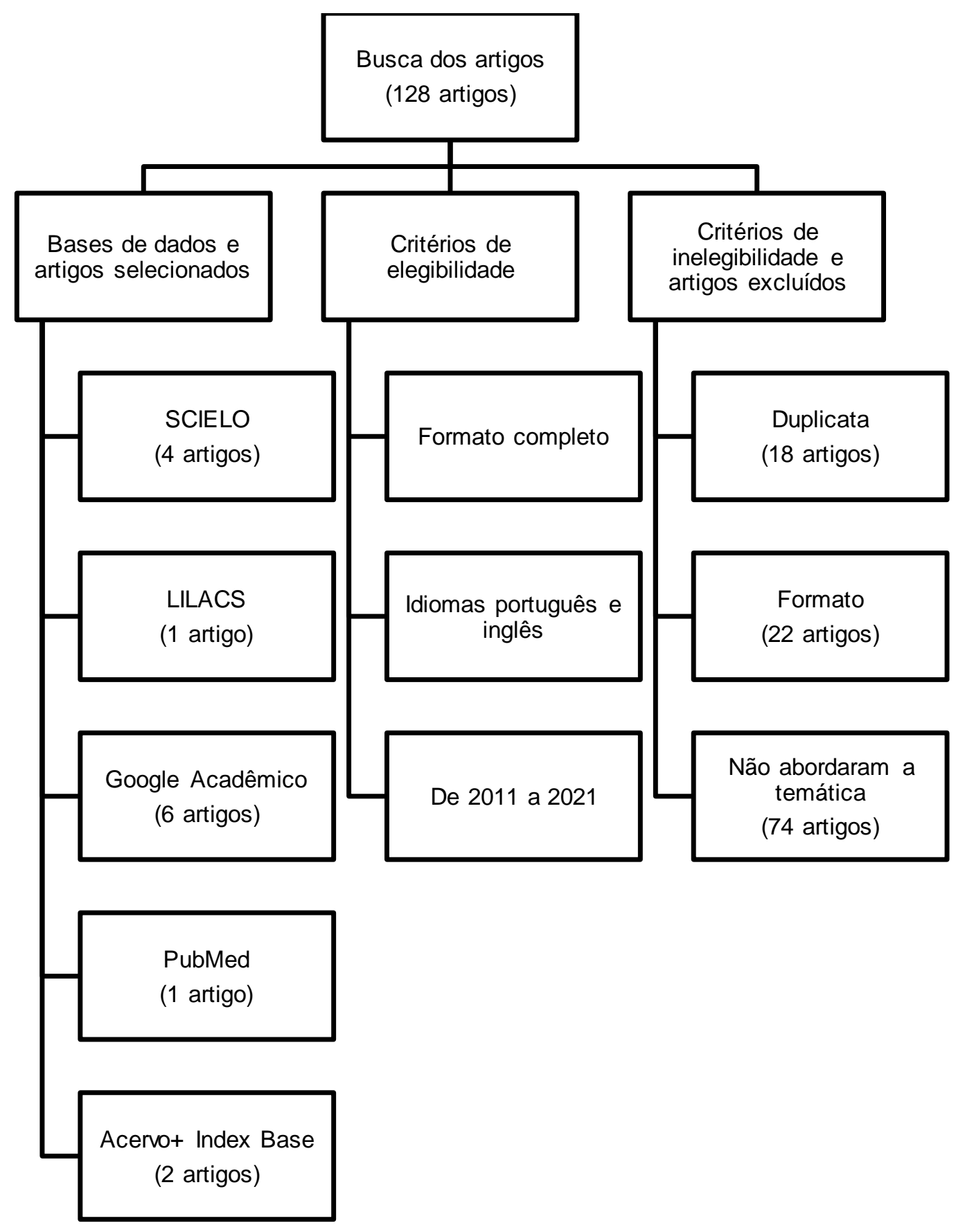

Fonte: Silva SNP, et al., 2021.

Os artigos selecionados para a elaboração deste estudo e desenvolvimento das categorias, foram organizados e estão descritos no Quadro 1. 
Quadro 1 - Descrição dos artigos selecionados.

\begin{tabular}{|c|c|c|c|c|}
\hline Título & Idioma & Autores & Base & RESULTADOS \\
\hline $\begin{array}{l}\text { Fatores intervenientes do desmame } \\
\text { precoce durante o aleitamento } \\
\text { materno exclusivo. }\end{array}$ & Português & $\begin{array}{l}\text { Araujo SC, et } \\
\text { al., } 2021 .\end{array}$ & $\begin{array}{l}\text { Acervo+ } \\
\text { Index Base }\end{array}$ & $\begin{array}{l}\text { O AME traz uma contribuição singular para a formação das habilidades de } \\
\text { cognição infantil, principalmente no que tange a área escolar, onde se pode } \\
\text { constatar Ql elevado em crianças que foram amamentadas de forma exclusiva } \\
\text { associada aos ácidos graxos presentes no leite materno, em relação aos que } \\
\text { utilizavam fórmula. }\end{array}$ \\
\hline $\begin{array}{l}\text { Fatores que influenciam o desmame } \\
\text { precoce e a extensão do } \\
\text { aleitamento. }\end{array}$ & Português & $\begin{array}{l}\text { Carrascoza KC, } \\
\text { et al., } 2015 .\end{array}$ & SCIELO & $\begin{array}{l}\text { Segundo dados de especialistas e autores que estudam as áreas da saúde e } \\
\text { social, muitos fatores, principalmente os sociais e econômicos, fazem o índice } \\
\text { de amamentação diminuir, causando problemas de saúde pública. }\end{array}$ \\
\hline $\begin{array}{l}\text { Aleitamento Materno Exclusivo: Fator } \\
\text { de Proteção para a Obesidade } \\
\text { inf antil? }\end{array}$ & Português & $\begin{array}{l}\text { Elizeu MG e } \\
\text { Guissoni FM, } \\
\quad 2016 .\end{array}$ & $\begin{array}{l}\text { Google } \\
\text { Acadêmico }\end{array}$ & $\begin{array}{l}\text { Um dos inúmeros motivos que incidem para a permanência a AME até os } 06 \\
\text { meses de idade está na relação entre o aleitamento materno e os seus } \\
\text { benefícios tanto para mãe, quanto ao bebê, visto que se for inserido o uso de } \\
\text { mamadeiras, colabora para o ganho de peso infantil, uma vez que a criança } \\
\text { passa a consumir uma quantidade maior que as suas necessidades de leite, } \\
\text { proteínas e açúcares. }\end{array}$ \\
\hline $\begin{array}{l}\text { Fatores associados ao desmame } \\
\text { precoce no aleitamento materno. }\end{array}$ & Português & $\begin{array}{l}\text { Fialho FA, et al., } \\
\qquad 2014 \text {. }\end{array}$ & SCIELO & $\begin{array}{l}\text { O tabagismo é uma outra questão que leva ao DP, assim como o grau de } \\
\text { escolaridade da mãe. Existem estudos que apontam que mães casadas } \\
\text { praticam mais o AME uma vez que recebem apoio e incentivo por parte do } \\
\text { cônjuge; de igual modo se a mãe é primípara ou multípara. }\end{array}$ \\
\hline $\begin{array}{l}\text { Causas e consequências do } \\
\text { desmame precoce e as intervenções } \\
\text { dos profissionais enfermeiros }\end{array}$ & Português & $\begin{array}{l}\text { Figueiredo JTC, } \\
\text { et al., } 2019 .\end{array}$ & $\begin{array}{l}\text { Google } \\
\text { Acadêmico }\end{array}$ & $\begin{array}{l}\text { A mortalidade infantil possui finalidade com o DP, pois grande parte dos óbitos } \\
\text { ocorridos em crianças menores de cinco anos são associados a interrupção do } \\
\text { AME, pois, a instrução da AC antes da necessidade fisiológica do bebê tanto } \\
\text { pode propiciar para a obesidade como para desnutrição e até mesmo influenciar } \\
\text { no desenvolvimento natural inf antil. }\end{array}$ \\
\hline $\begin{array}{l}\text { Linkages of Nursing Diagnoses, } \\
\text { Outcomes, and Interventions } \\
\text { Performed by Nurses Caring for } \\
\text { medical and Surgical Patients Using } \\
\text { a Decision Support System. }\end{array}$ & Inglês & $\begin{array}{l}\text { Gengo e, et al., } \\
2018 .\end{array}$ & PubMed & $\begin{array}{l}\text { Apesar dos obstáculos que os (as) enfermeiros(as) enfrentam para implementar } \\
\text { a SAE, suas contribuições significativas devem ser levadas em conta, propondo } \\
\text { um momento de reflexão pelos profissionais de enfermagem, especialmente } \\
\text { os(as) enfermeiros(as). }\end{array}$ \\
\hline $\begin{array}{l}\text { Relação entre desmame precoce e } \\
\text { alergias alimentares }\end{array}$ & Português & $\begin{array}{l}\text { José DKB, et al., } \\
2017 .\end{array}$ & $\begin{array}{l}\text { Google } \\
\text { Acadêmico }\end{array}$ & $\begin{array}{l}\text { A prática do desmame precoce resulta também em maiores taxas de propensão } \\
\text { a alergias alimentares. }\end{array}$ \\
\hline
\end{tabular}




\begin{tabular}{|c|c|c|c|c|}
\hline Título & Idioma & Autores & Base & RESULTADOS \\
\hline Investigação das práticas maternas & Português & $\begin{array}{l}\text { Nadal LF, et al., } \\
\qquad 2017 .\end{array}$ & SCIELO & $\begin{array}{l}\text { Além dos efeitos protetores, o aleitamento natural propicia um bom } \\
\text { posicionamento do lactente durante a amamentação devido ao apoio de sua } \\
\text { cabeça no braço da mãe em uma altura mais horizontalizada, evitando que o } \\
\text { leite escorra pela tuba auditiva. Portanto, a amamentação exclusiva é segura, } \\
\text { promove o desenvolvimento sensorial e cognitivo e contém anticorpos que } \\
\text { protegem as crianças de doenças comuns da infância. }\end{array}$ \\
\hline $\begin{array}{l}\text { Aleitamento materno: consequências } \\
\text { do desmame precoce e o papel da } \\
\text { enfermagem: uma revisão } \\
\text { bibliográfica }\end{array}$ & Português & $\begin{array}{l}\text { Oliveira AS e } \\
\text { Carniel F, } 2021 .\end{array}$ & $\begin{array}{l}\text { Acervo+ } \\
\text { Index Base }\end{array}$ & $\begin{array}{l}\text { O DP pode ser influenciado por uma série de fatores como a oferta de outros } \\
\text { tipos de alimentação antes que o bebêcomplete seis meses que não seja o leite } \\
\text { materno. Tal influencia pode se dar por situações as quais a mãe está expos ta } \\
\text { e interferem de forma direta no AME como hospitalização e baixo peso ao } \\
\text { nascimento e a recusa da pega do bebê. }\end{array}$ \\
\hline $\begin{array}{l}\text { Aleitamento Materno: fatores que } \\
\text { levam ao desmame precoce no } \\
\text { município de Passo Fundo, RS }\end{array}$ & Português & $\begin{array}{l}\text { Parizotto J, } \\
\text { Zorzi NT, } 2018 .\end{array}$ & $\begin{array}{l}\text { SCIELO, } \\
\text { LILACS }\end{array}$ & $\begin{array}{l}\text { Observando as dificuldades de cada mãe, constatou-se a necessidade de ajuda } \\
\text { do profissional. A visita domiciliar propicia um acompanhamento das } \\
\text { participantes por meio da visita domiciliar, a qual favorece o vínculo entre o } \\
\text { profissional e o paciente. Porém, elas não seguem a maior parte das } \\
\text { informações e continuam a acreditar e valorizar suas crenças e tabus, agindo } \\
\text { por conta própria no momento de introduzir outros alimentos antes dos seis } \\
\text { meses, de acordo com os hábitos da família. }\end{array}$ \\
\hline $\begin{array}{l}\text { Consequências e intervenções de } \\
\text { enfermagem no aleitamento materno } \\
\text { e a prevenção do desmame precoce }\end{array}$ & Português & $\begin{array}{l}\text { Passos ET, et } \\
\text { al., } 2021 .\end{array}$ & $\begin{array}{l}\text { Google } \\
\text { Acadêmico }\end{array}$ & $\begin{array}{l}\text { A prática do DP influencia de forma direta a mãe e o bebê, trazendo } \\
\text { consequências nutricionais que podem acarretar doenças no sistema digestóno } \\
\text { e respiratório, adiposidades, alergias, e muitas outras, além de ocasionar } \\
\text { adversidades no vínculo materno }\end{array}$ \\
\hline $\begin{array}{l}\text { Aleitamento materno: causas e } \\
\text { consequências do desmame } \\
\text { precoce. }\end{array}$ & Português & $\begin{array}{l}\text { Silva DP, et al., } \\
\quad 2017 .\end{array}$ & $\begin{array}{l}\text { Google } \\
\text { Acadêmico }\end{array}$ & $\begin{array}{l}\text { As crianças que não usufruíram o AME durante os primeiros } 6 \text { meses de vida } \\
\text { constatou-se uma baixa imunidade, além de predisposição elevada a anemias } \\
\text { e um retardo do desenvolvimento infantil. }\end{array}$ \\
\hline $\begin{array}{l}\text { Diagnósticos de enfermagem } \\
\text { relacionados à amamentação em } \\
\text { unidade de alojamento conjunto }\end{array}$ & Português & Silva EP, 2013. & SCIELO & $\begin{array}{l}\text { O DP relaciona-se diretamente à prematuridade e é caracterizado pelo apartar } \\
\text { entre mãe e filho. }\end{array}$ \\
\hline $\begin{array}{l}\text { A atuação do (a) enfermeiro (a) na } \\
\text { promoção, incentivo e apoio ao } \\
\text { aleitamento materno: revisão } \\
\text { bibliográfica }\end{array}$ & Português & $\begin{array}{l}\text { Marinho MS, et } \\
\quad \text { al. } 2015 \text {. }\end{array}$ & $\begin{array}{l}\text { Google } \\
\text { Acadêmico }\end{array}$ & $\begin{array}{l}\text { Por ser o profissional mais próximo da gestante durante o período de pré-natal, } \\
\text { e por possuir conhecimento técnico-científico, o enfermeiro é de suma } \\
\text { importância para a promoção do aleitamento materno, pois através de seus } \\
\text { conhecimentos é capaz de incentivar e apoiar tanto a gestante quanto sua } \\
\text { família por meio de ações e educação em saúde. }\end{array}$ \\
\hline
\end{tabular}

Fonte: Silva SNP, et al., 2021. 


\section{Os Impactos Gerados Pelo Desmame Precoce}

Existem vários impactos decorrentes do DP, dentre ao quais os principais são: Amamentação ineficaz; Alergia Alimentar; Danos fonoarticulatórios; Obesidade e Diarreia. Além disso, segundo Silva EP (2013), o DP relaciona-se diretamente à prematuridade e é caracterizado pelo apartar entre mãe e filho, levando à diminuição de vínculo af etivo e posterior diminuição de hormônios da lactação.

De acordo com Gouvea RCL e Trindade JSB (2016), a suç̧ão decorrente do aleitamento materno oportuniza um melhor e pleno crescimento facial, sem desvios, onde estão inseridas a fonação, a respiração nasal, a mastigação, a deglutição e a posição adequada da língua e dos lábios. De outro ponto de vista podese observar os hábitos associados às questões de alteração no crescimento ósseo, mal posicionamento dentário e prejuízos na fala como, por exemplo, o hábito de sugar chupetas e o próprio dedo, a respiração bucal, as funções anormais da língua durante a deglutição, fonação e postura, dentre outros.

Na questão relacionada aos impactos, Marcondes E, et al. (2013) diz que, a interrupção parcial ou total do AM antes que o bebê complete os seis meses de vida caracteriza o desmame precoce DP, não dependendo da causa que levou a mãe a tal prática. A of erta de qualquer outro alimento como chás, cereais e vitaminas e, até mesmo, leite que não seja de origem humana no decorrer dos primeiros seis meses do RN, também caracteriza o DP.

Segundo o estudo de Oliveira AS e Carniel F (2021), o DP pode ser influenciado por uma série de fato res como a of erta de outros tipos de alimentação antes que o bebê complete seis meses que não seja o leite materno. Tal influencia pode se dar por situações as quais a mãe está exposta como traumas, mastites, ingurgitamento mamário, fissuras e rachaduras mamilares, retorno ao trabalho, depressão, nível de escolaridade, baixa renda, idade materna além a of erta de chupetas, mamadeiras e outros, além de agravos fisiológicos que interferem de forma direta no AME como hospitalização e baixo peso ao nascimento e a recusa da pega do bebê.

A prática do DP influencia de forma negativa e direta tanto a mãe como o bebê, trazendo consequências nutricionais que de acordo com Parizotto J e Zorzi NT (2018), podem acarretar doenças no sistema digestónio e respiratório, adiposidades, alergias, otites, baixo peso, baixa imunidade, crescimento reduzido, neoplasias de mama, ovários e útero, infecções oportunistas, além de ocasionar adversidades no vínculo materno.

José DKB, et al. (2017), apontam que o DP acarreta, também, na elevação das taxas de casos de alergias alimentares, uma vez que as mães acreditam que o leite não humano é melhor do que o que elas produzem e, com isso, o acabam introduzindo alimentação do bebê de forma precoce, gerando, assim, as alergias alimentares, pois o sistema digestivo e imunológico do bebê ainda é imaturo antes que completem os seis meses de idade.

A interrupção do AM de acordo com Parizotto J e Zorzi NT (2018), dá-se em virtude de as mães possuírem crenças e tabus que se transmite de geração a geração, como entenderem que o leite o qual produzem não é quantidade suficiente para satisfazer as necessidades de seu bebê ou, ainda, que o leite é fraco devido sua aparência aguada, bem como algumas situações anatômicas como o formato do bico mamilar invertido ou plano, além da interferência dos familiares mais velhos os quais compreendem que o AME não é necessário por seis meses, e dizem que se deve inserir outros alimentos, antecedendo es se tempo.

O AME traz uma contribuição singular para a formação das habilidades de cognição inf antil, principalmente no que tange a área escolar, e de acordo com Araujo SC, et al. (2021), pode-se constatar Ql elevado em crianças que foram amamentadas de forma exclusiva associada aos ácidos graxos presentes no leite materno, em relação aos que utilizavam fórmula.

Para Passos ET, et al. (2021), a causa de $20 \%$ das intolerâncias a lactoses é a inclusão do leite de vaca na alimentação da criança antecedente a 1 ano de vida, pois este alimento contém alta quantidade de antigênico e o aparelho digestivo infantil ainda se encontra imaturo para o recebimento dessa dieta.

Ao inserir alimentos complementares na dieta do bebê em período inferior ao recomendado tanto pela OMS como pelo MS, de acordo com Alves ES (2018), pode acarretar em prejuízos na absorção de nutrientes, 
uma vez que a quantidade de nutrições administradas durante o dia geralmente é insuficiente para as necessidades fisiológicas do bebê, além de ser carente em energéticos e quantidades de micro e macronutrientes são irregulares a idade nutricional. Apesar dos impactos serem características mais ríspidas a crianças inferiores a 6 meses, Alves ES (2018) também diz que, a administração de dieta na idade correta, porém de maneira negligente podem ocasionar consequências também.

Para Figueiredo JTC, et al. (2019), o DP está correlacionado a mortalidade infantil, uma vez que grande parte dos casos de óbitos sofridos por crianças menores de cinco anos decorrem da interrupção do AME, além de propiciar para a obesidade como para desnutrição e até mesmo influenciar no desenvolvimento natural infantil.

Segundo dados de especialistas e autores como que estudam as áreas da saúde e social, muitos fatores, principalmente os sociais e econômicos, fazem o índice de amamentação diminuir, causando problemas de saúde pública (CARRASCOZA KC, et al. (2015).

Porém, podemos ressaltar um outro lado pouco observado e falado que é o DP pela participação da mulher na sociedade capitalista, juntamente com a falta de conhecimento sobre o benefício do aleitamento. Através dessas informações, juntamente com as consequências a longo prazo, como diminuição da qualidade de vida das famílias, causadas pelo desmame e com as informações fornecidas pelos especialistas da área, podemos conferir os impactos diretos e diretos causados pelo desmame precoce (FIALHO FA, et al., 2014).

\section{Os Benefícios do Aleitamento Materno (AM)}

É importante ressaltar que o aleitamento materno, por não ser um ato instintivo e assim comportamental, deve ser adquirido e aprendido. E de acordo com Marcondes E, et al. (2013), o AME contém diversos nutrientes que garantem sobrevida e crescimento saudável a criança, promovendo também um bom desenvolvimento motor, cognitivo e sensorial, além de ser um meio de prevenção contra muitos problemas como obesidade infantil, infecções intestinais, hipertensão, diabetes e outros.

Dentre os benefícios é relevante citar sua importância para a mãe, para a criança e para a família, a instituição e a sociedade. Quando se trata da mãe, Silva EP (2013) aponta que, durante a amamentação ocorre o menor sangramento pós-parto e consequentemente a menor incidência de anemias e sua recuperação é mais rápida para voltar ao peso pré-gestacional, no entanto, com o abandonar precocemente a mãe perde a proteção natural contra a concepção e fica propicia ao câncer de mama e ovário.

Crianças amamentadas corretamente segundo Paula LM e Pereira ES (2013), apresentam menores índices de alergias em geral, menos infecções, diarreia e outros, em virtude das características e dos anticorpos que compõe o LM, assim como enzimas digestivas, fatores antimicrobiano e anti-inflamatórios, o que promove a redução de internações hospitalares e a morbidade decorrente por diarreia, portanto as crianças que recebem o AME até os 06 meses estão mais disponíveis a esta proteção.

De modo geral o AME garante vários benefícios como: economia com a alimentação do recém -nascido, economia em consultas médicas, medicamentos, exames laboratoriais e hospitalização da criança, Redução dos gastos institucionais com aquisição de fórmulas, frascos, bicos artificiais e medicamentos (ocitocina), no entanto, para Elizeu MG e Guissoni FM (2016) um dos inúmeros motivos que incidem para o benefício do AM até os 06 meses de idade está na relação entre o AM e o controle do sobrepeso e da obesidade infantil, visto que o uso de mamadeiras colabora para o ganho de peso infantil, uma vez que a criança passa a consumir uma quantidade maior que as suas necessidades de leite, proteínas e açúcares.

Segundo o North American Nursing Diagnoses Association (NANDA, 2018), é primordial que a mãe seja orientada principalmente pela enfermagem a manter o AME, pois mediante as orientações a mãe irá of ertar apenas o leite materno até que o bebê complete 6 meses de idade, e não irá of ertar outros alimentos, tampouco água ou chás ao bebê nos primeiros seis meses de vida, pois o leite materno já contém bastante nutrientes, principalmente a água.

Em conformidade com o Ministério da Saúde (2019) e Paula LM e Pereira ES (2013) o AM é capaz de proteger as crianças contra infecções, diarreia e outros, em virtude de suas características e dos anticorpos 
que o compõe, assim como enzimas digestivas, fatores antimicrobiano e anti-inflamatórios, o que promove a redução de internações hospitalares e a morbidade decorrente por diarreia, sendo que as crianças que recebem o AME até os 06 meses estão mais disponíveis a esta proteção.

Segundo Nadal LF, et al. (2017), os recém-nascidos alimentados com AME apresentam menor possibilidade de contrair infecções, já que esse leite é estéril, isento de bactérias, e o colostro, assim como a continuação da amamentação, ajuda a proteger o recém-nascido até que ele comece a produzir os seus próprios anticorpos, pois, contém fatores de defesa que eliminam as bactérias e agem contra infecções mais comuns.

Entretanto, Gouvea RCL e Trindade JSB (2016) relata que, caso a mãe, mesmo após o parto, não conseguir amamentar o bebê, ela poderá amamentá-lo com saúde através dos bancos de leite. O Brasil possui vários bancos de leite espalhados pelas principais cidades que são, inclusive, premiados internacionalmente quando à confiança e à qualidade. O leite é devidamente examinado e pasteurizado, eliminando vírus e bactérias sem destruir as suas proteínas.

Aliás, a excelência do AM pode ser verificada sob diversos prismas. De acordo com Silva DP, et al. (2017), para o consumo do leite materno não há necessidade de comprá-lo ou armazená-lo, pois este já está pronto, na temperatura adequada, não havendo possibilidade de contaminação, além disto, dispensam bicos, mamadeiras, esterilização, a criança também não precisa receber água ou chás, sendo que um outro fator também importante é a realização feminina, na medida em que se completa o processo da maternidade.

\section{A importância das Ações da Enfermagem para o sucesso do Aleitamento Materno Exclusivo}

Durante o pré-natal, de acordo com Marinho MS, et al. (2015), as ações do enfermeiro para incentivo da amamentação e para sanar dúvidas das gestantes são extremamente importantes e servem de apoio neste período de grandes transformações. Além disso, conforme Gengo E, et al. (2018), assistir à mãe e a criança em processo de aleitamento materno é importante para ressaltar que ambos precisam aprender como fazer, especialmente, quando é a primeira experiência da mulher.

A vivência anterior pode contribuir positiva ou negativamente, dependendo de como essa experiência aconteceu. E de acordo com Oliveira AS e Carniel $F$ (2021), mesmo que já tenha vivido uma experiência anterior em amamentar, percebe-se que situações novas se apresentam em decorrência do momento ser outro e do filho ser diferente.

Neste sentido, Brasil (2018) diz que, o apoio e a assistência da enfermagem são fundamentais, uma vez que a mulher tem nesse profissional de saúde a segurança de que, o enfermeiro pode oferecer soluções diante das dificuldades, pois é um profissional capacitado para orientar, conscientizar e sanar dúvidas a respeito do AME desde as consultas de pré-natal. Dessa forma, ao contar com o apoio do enfermeiro, o aleitamento será um momento prazeroso para mãe e para o bebê. Ademais, a equipe multidisciplinar deve demonstrar confiança e apoio à paciente, aceitando o que a mãe sente e pensa e fornecer ajuda prática, mantendo-se atualizada em seu conhecimento para melhor contribuir, evitando assim o DP (BRASIL, 2018).

\section{CONSIDERAÇÕES FINAIS}

Como foi descrito aqui o leite materno é o melhor alimento para ser fornecido a criança desde o seu nascimento, até que esta complete os seis meses de vida, por ser completo e já está pronto, na temperatura ideal, tem baixo custo, devendo ser complementado com outros tipos de alimentos apenas a partir dos seis meses. O leite materno assegura a criança uma boa nutrição na fase inicial de sua vida, além de fortalecer seu sistema imunológico de forma gradativa, protegendo o bebêde futuras patologias. Os benefícios oriundos do leite materno não estão limitados às crianças, pois ele também favorece a mãe por inúmeras substâncias contidas no leite, as quais promovem a proteção contra diversas patologias dentre elas o câncer de mama, de útero e de ovário. Nesse ínterim, é imprescindível fornecer as mães informações acerca dos benefícios que o AME promove tanto para a mãe como para o bebê, demonstrando-lhe os riscos provenientes do desmame precoce. 


\section{REFERÊNCIAS}

1. ALVES ES. Análise da influência do desmame precoce no estado nutricional das crianças. Trabalho de Conclusão de Curso (especialização em Atenção Básica em Saúde). Universidade Federal de Minas Gerais (UFMG), Araçuaí, 2018; $37 \mathrm{p}$.

2. ARAÚJO OD, et al. Aleitamento materno: fatores que levam ao desmame precoce. Revista Brasileira de Enfermagem, 2008;61(4): 488-492.

3. ARAUJO SC, et al. Fatores intervenientes do desmame precoce durante o aleitamento materno exclusivo. Revista Eletrônica Acervo Saúde, 2021;13(4): e6882.

4. BOTELHO LLR, et al. O método da revisão integrativa os estudos organizacionais. Gestão e Sociedade, 2011;5:121 136.

5. BRASIL. OMS e UNICEF lançam novas orientações para promover aleitamento materno em unidades de saúde de todo $\quad 0 \quad$ mundo. $2018 . \quad$ Disponível em: https://www.paho.org/bra/index.php?option=com_content\&view=article\&id=5631 :omse-unicef-lancam-novasorientacoes-para-promover-aleitamento-materno-em-unidadesde-saude-de-todo-o-mundo\&ltemid=820. Acessado em:21 de setembro 2021.

6. CARRASCOZA KC, et al. Fatores que influenciam o desmame precoce e a extensão do aleitam ento. Revistas estudos de psicologia, 2015;22(4):433-440.

7. COSTA EC. Caracterização microbiológica físico química do leite materno em diferentes períodos da lactação. Dissertação (Mestrado em Ciências e tecnologia de alimentos). Universidade Federal de Viçosa, Viçosa Minas Gerais, 2012;97 p.

8. ELIZEU MG, GUISSONI FM. Aleitamento Materno Exclusivo: Fator de Proteção para a Obesidade infantil?. Saúde em Revista, 2016;16(44):15-24.

9. FIALHO FA, et al. Fatores associados ao desmame precoce do aleitamento materno. Revista Cuidarte, 2014; 5(1): 670-678.

10. FIGUEIREDO JTC, et al. Causas e consequências do desmame precoce e as intervenções dos profissionais enfermeiros. Rev. Cienc. Saberes UniFarma. 2019;4(3): 1158-63.

11. GENGO E, et al. Linkages of nursing diagnoses, outcomes, and interventions performed by nurses caring for medical and surgical patients using a decision support system. Int. J. Nurs. Knowl, 2018;29(4): 269-75.

12. GOUVEA RCL, TRINDADE JSB. Hábitos não nutritivos: uso da mamadeira, chupeta e sucção digital. Graduação. Centro Universitário São Lucas, Porto Velho, 2016;16p

13. JOSÉ DKB, et al. Relação entre desmame precoce e alergias alimentares. Visão Acadêmica, 2017;17(3):66 -74.

14. LEÃO E, et al. Pediatria Ambulatorial.4aㅡ Ed. Belo Horizonte:Editora Coopmed, 2015;314-320p.

15. MARCONDES, Eduardo. Pediatria Básica. 9. ed. São Paulo: Editora Sanvier, 2013.

16. MARINHO MS, et al. A atuação do (a) enfermeiro (a) na promoção, incentivo e apoio ao aleitamento materno: revisão bibliográfica. Revista Enfermagem Contemporânea, 2015;4(2):189-198.

17. MARQUES ES, et al. Mitos e crenças sobre o aleitamento materno. Revista Ciência e saúde Coletiva, 2011; 16(5): 2468.

18. MINISTÉRIO DA SAÚDE. Leite materno contém todos os benefícios para a saúde do bebê. 2019. Disponível em: http://www.blog.saude.gov.br/index.php/promocao-dasaude/53881-doar-leite-salva-vidas. Acessado em: 21 de setembro de 2021.

19. MINISTÉRIO DA SAÚDE. Cadernos de atenção básica. Saúde da criança: aleitamento materno e alimentação complementar. $2015 . \quad$ Disponível em https://bvsms.saude.gov.br/bvs/publicacoes/saude_crianca_aleitamento_materno_cab23.pdF. Acessado em: 21 de setembro de 2021.

20. MINISTÉRIO DA SAÚDE. Secretaria de Atenção à Saúde. Departamento de Atenção Básica. Saúde da criança: aleitamento materno e alimentacão complementar. $2^{\underline{a}}$ ed. Brasília: Ministério da Saúde, 2015. Disponível em: https://bvsms.saude.gov.br/bvs/publicacoes/saude_crianca_aleitamento_materno_cab23.pdf. Acessado em: 21 de setembro de 2021.

21. NADAL LF, et al. Investigação das práticas maternas sobre aleitamento materno e sua relação com a infecção de vias aéreas superiores e otite média. Revista CEFAC, 2017;19: 387-394.

22. North American Nursing Diagnoses Association (NANDA). NANDA INTERNATIONAL. Diagnósticos de enfermagem

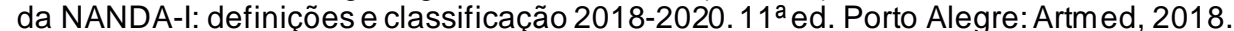

23. OLIVEIRA AS, CARNIEL F. Aleitamento materno: consequências do desmame precoce e o papel da enfermagem: uma revisão bibliográfica. Revista Eletrônica Acervo Científico, 2021;20(1): e5659.

24. PARIZOTTO J, ZORZI NT. Aleitamento Materno: fatores que levam ao desmame precoce no município de Passo Fundo, RS. O mundo da Saúde, 2018;32(4): 466-74.

25. PASSOS ET, et al. Consequências e intervenções de enfermagem no aleitamento materno e a prevenção do desmame precoce. Rev. Bras. Interdiscip. Saúde (ReBIS), 2021;3(3): 33-9.

26. PAULA LM, PEREIRA ES. Eficácia do aleitamento materno contra a diarreia infantil: uma revisão sistemática. Repositório Pontifícia Universidade Católica de Goiás, 2013.

27. SCHNEIDER A, et al. O papel do aleitamento materno, da dieta e do estado nutricional no desenvolvimento de asma e atopia. Jornal Brasileiro de pneumologia, 2017;33:454-62.

28. SILVA DP, et al. Aleitamento materno: causas e consequências do desmame precoce. Unimontes Científica, 2017; 19(2): 147-157.

29. SILVA EP. Diagnósticos de enfermagem relacionados à amamentação em unidade de alojamento conjunto. Rev Bras Enferm, 2013;66(2):190-5.

30. SILVA JN. Aleitamento materno: motivos e consequências do desmame precoce em crianças. Revista Artigos. Com, 2020;20: e4756. 